\title{
Research Status and Prospects of Vibro Ripper
}

\author{
Liu Zenghui ${ }^{1}$, Yang Guoping ${ }^{1}$, Cao Guojun ${ }^{2}$ \\ ${ }^{1}$ (Automotive Engineering College, Shanghai University Of Engineering Science, Shanghai 201620, China) \\ ${ }^{2}$ (Shanghai Shining Mechanical Technology Co. Ltd, Shanghai, 201804, China)
}

\begin{abstract}
This Paper First Introduces The Basic Structure And Basic Principle Of The Vibro Ripper, And Introduced The Advantages. Based On The Practical Operation Experiences And The Characteristics Of HighFrequency Vibro Ripper, Comebine The Research Of Traditional Hydraulic Hammer, The Vibro Ripper Broken Mechanism Is Proposed, This Paper Also Analyse The Current Research Matters Of Vibro Ripper, And Put Forward The Optimization Method Of The High-Frequency Vibro Ripper, And Prospect The Future Development Direction Of Vibro Ripper.
\end{abstract}

Keywords: - Breaking Way, Efficiency, Piston Breaker, Vibro Ripper

\section{INTRODUCTION}

Vibro Ripper Is A New Type Of Hydraulic Breaking Hammer ${ }^{[1]}$, It's Very Popular Since It Appear, Crusher Is Widely Used In Mine Rock, Project Construction, Especially The Transformation Of The Old City, Broken Of Concrete Member. This Article Analyze Its Advantages From Broken Mechanism And Method, And Compared The Efficiency Of Both Breaking Hammer, Put Forward The Optimization Method Of Vibro Ripper, And Analyzes The Market Positioning Of High-Frequency Vibro Ripper.

\section{The Basic Structure And Working Principle Of Vibro Ripper}

\subsection{The Structure Characteristics Of Whole Machine}

Main Structure Of Vibro Ripper As Shown In Figure 1, It Consists Of Frame, Vibration Box And Upper And Lower Pull Rod, There Is A Pair Of Meshed Eccentric Gear In The Vibration Box, Exciting Force F Is Produced By Hydraulic Motor Drive The Eccentric Wheel Rotation, Which Can Make The Vibration Box Compress Air Spring Relative To Frame, Through Upper And Lower Pull Rod To Control The Displacement Of Vibration Box, Vibration Box Through Tool-Array That Welding At The Bottom Of Box And The Bucket Tooth Transmit Vibration Force To Rock.

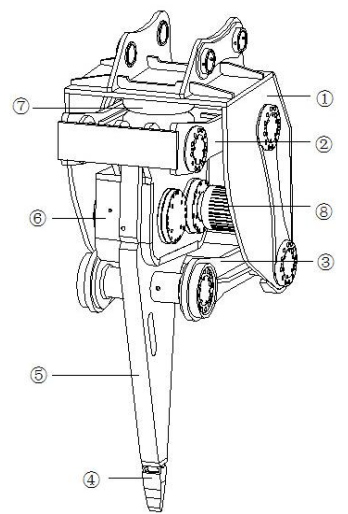

(1) - Frame, (2) - Upper Pull Rod, (3) - Lower Pull Rod, (4)- Dipper Teeth, (5) - Tool-Array,(6) Vibration Box,(7) - Buffer Device,(8) -Hydraulic Motor

Fig.1 Structure Of Vibro Ripper

\subsection{Working Principle Of The Vibro Ripper}

Hydraulic Motor Drive The Eccentric Wheel To Rotate, Which Can Produce Vibration Force F, Therefore, Vibration Box Compress Air Spring Relative To Frame, Which Can Stored Energy To Reduce The Impact On The Frame. Vibration Box Through Tool-Array And The Bucket Tooth Transmit Vibration Force To Rock; Vibration Box, Tool-Array And Dipper Teeth Through Welding As One Part, And This Part Is Named Vibrator. Vibrator Box Through Upper Pull Rod And Lower Pull Rod Connect Frame To Constitute A Parallel Four-Link Mechanism, Which Can Make The Translation Of Vibrator Along The Vertical Surface, Parallel 
Four-Link Mechanism Can Insure The Accuracy Of The Striking Point, Which Can Make The Bucket Tooth Effect On Rock Surface Effectively.

The Exciting Force Of Vibrator Is:

$$
\mathrm{F}=2 \mathrm{me} \omega 2 \sin \omega \mathrm{T} \quad(1)
$$

M-The Quality Of The Eccentric Block; E- Eccentricity Of Eccentric Block; $\omega$-The Rotation Angular Velocity Of The Eccentric Block, $\omega=60 \mathrm{n} / 2 \pi$

The Speed Of Vibro Ripper Is Associated With The Rotation Speed Of Hydraulic Motor That Is Related To The Hydraulic Flow Rate Which Offered By Excavator. According To The Working Principle Of Hydraulic Motor, Hydraulic Flow Determines The Motor Rotation Speed And Hydraulic Pressure Determines The Size Of The Motor Torque. If The Pressure Is Certain, The Greater Hydraulic Flow Rate, The Faster Rotation Speed, The Impact Force That Produced By Vibro Ripper Is Greater; The Frequency Of The Blow Is $1300 \sim 3000$ Times/Min.

\section{The Advantages Of Vibro Ripper}

Compared With The Traditional Piston Hammer, There Are Many Advantages For Vibro Ripper: (1) Minimization Of Noise Pollution, The Noise Is Only $55 \sim 70$ Db When Working, Meet The Urban Construction Noise Standard;(2) It Doesn't Produce Black Oil Or Damage To The Main Pump And Oil Cylinder, Which Is Friendly For Excavators;(3) It Can Achieve Underwater Broken Without Any Refit;(4) It Has Less Wearing Parts, Maintenance Quantity Is Little ${ }^{[2]}$.

\section{The Research On Vibro Ripper Broken}

Vibro Ripper As A New Type Of Breaking Hammer, Although Its Hit Frequency Is 3-5 Times Than Conventional Hammer, But Under The Rotation Speed Limit Of Hydraulic Motor, The Highest Frequency Is Not More Than 30hz, The Hit Frequency Is Very Small Compared With The Natural Frequency Of Rock, It Is Unlikely For Massive Rock Breakage To Adopt The Resonance Method, So The Breaking Mechanism Of Vibro Ripper Is Similar To The Conventional Piston Hammer ${ }^{[3]}$.

\subsection{Vibro Ripper Impact Model}

In Hitting Roc, The Traditional Hydraulic Hammer Through The Piston Impact Drill Rod, Drill Rod Release Force To Broken Rock In The Vertical Direction; And Due To Vibrator And Frame Through Two Pair Pull Rods To Connect, So The Moving Track Of Vibrator Is A Circular Arc Rather Than A Straight Line, Therefore, The Bucket Tooth Produce Longitudinal Displacement.

The Longitudinal Amplitude:

$$
\mathrm{S}=\mathrm{L}(1-\cos \beta)
$$

Formula: L- Rod On The Two Holes Distance L To Tie On Two Holes Distance B-The Angle Change Of The Pull Rod

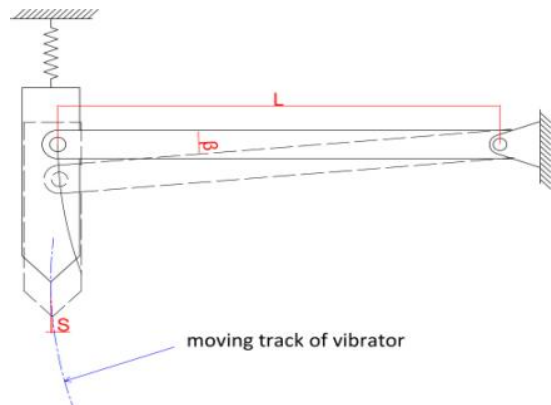

Fig.2 A Simplified Theoretical Model

In This Formula, The Amplitude Of Vibro Ripper Increase With The Increase Of Pull Rod Length And The B Angle.

\subsection{Breaking Way Analysis Of The Two Kinds Breaking Hammer}

According To The Analysis Of Traditional Hydraulic Hammer Broken, Breaking Ways Mainly Have The Several Ways:

(1)Smashing Rock - Refers To The Rock Is Isolated, Hammer Impact The Isolated Rock To Make The Isolated Rock Fracture (Fig 3). This Way Represented By Mine Secondary Crushing Massive Rock. This Way Is Most Efficient For Traditional Hydraulic Hammer, But For Vibro Ripper, This Way Is Inefficient, Because Impact Strength Is Small And Part Of The Impact Effect On The Longitudinal. 


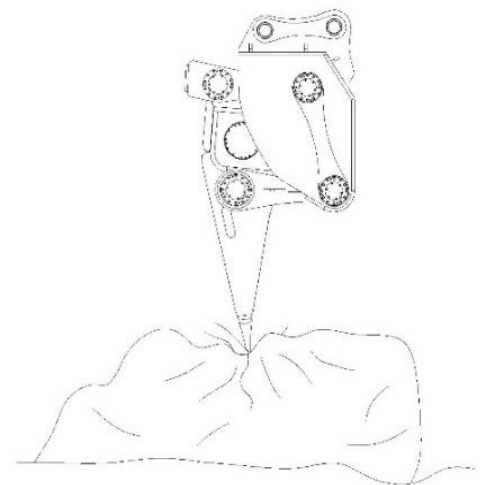

Fig.3 Smashing Rock

(2)Chiselling Rock-Refers To The Rock Just Have One Free Surface, Breaking Hammer Impact Rock Continuouslyjust The Surface Of Rock That Surround The Drill Rod Be Broken, And Broken Hole Is Formed (Fig 4). Due To The Impact Strength Of Vibro Ripper Is Small, This Way Is Most Inefficient For The Reason That The Impact Strength Of Vibro Ripper Is Low. However, For Traditional Hydraulic Hammer, This Way Is Very Efficient.

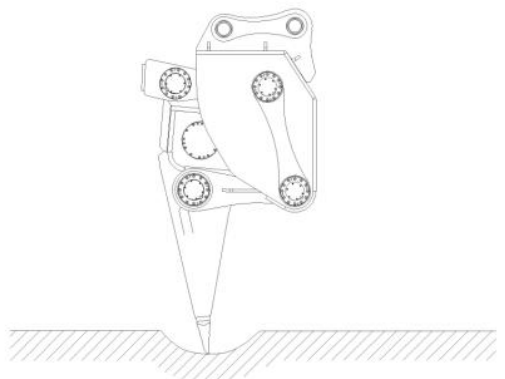

Fig.4 Chiselling Rock

(3) Spliting Rock-Refers To The Rock Have Two Free Surfaces, Drill Rod Chisel Into The Rock Near The Free Surface To Make The Rocks Separated From The Rock-Soil Body. This Way Is Represented By Direct Falling Rocks From Working Plane Using Vibro Ripper, Which Is The Main Way Of Rock Fragmentation, And It's Most Efficient Way For Vibro Ripper

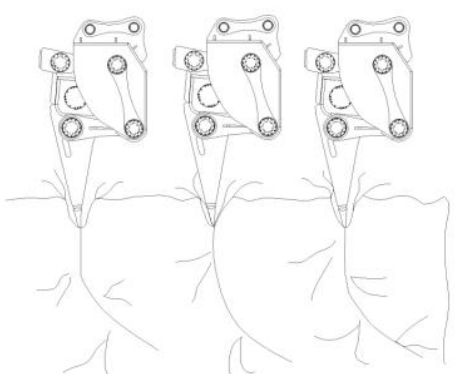

Fig.5 Spliting Rock

Through A Comparison Of The Three Breaking Way, We Can See That The Traditional Hydraulic Hammer Has Advantages In Smashing Rock And Chiseling Rock Ways, Especially For Large Hard Rocks; For Soft Rock, Such As The Weathered Rock And Shale, The Vibro Ripper Is More Efficient.In Addition, On The Other Hand, The Release Of The Impact Force Is Different For Vibro Ripper And Traditional Hydraulic Hammer; On The Other Hand, Due To The Shape Of The Tool-Array And Drill Rod Has Larger Differences, When They Contact With The Rock (Fig 3), The The Vibro Ripper Can Make Some Portion Impact Force Effect On Rock That Has Cut, Through The High Frequency Vibration To Make Rock Further Fracture (Fig. 3ta), Which Avoid The Secondary Crushing; But The Traditional Hydraulic Hammer Can Only Release The Impact Force On The Substratum Rock ${ }^{[4]}$, So In Many Cases, The Traditional Hydraulic Hammer Broken Frequently For A Long Time Make Hole (Fig. 3b), Which Greatly Reduces The Working Efficiency And Output, So, For The Breaking Hammer, Reasonable Structure Design With Reasonable Breaking Way Will Greatly Improve Production Efficiency. 


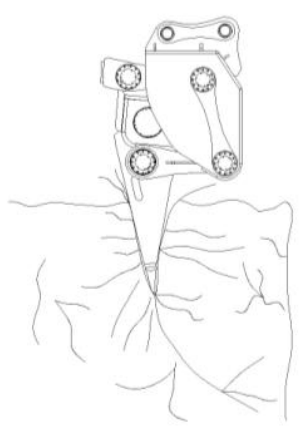

(a)

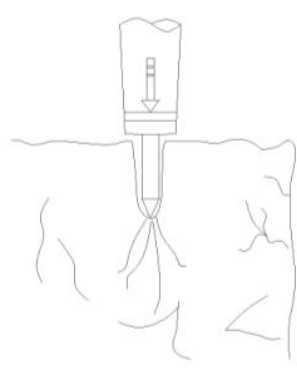

(B)

Fig.6 The Force Releasing Of The Two Kinds Breaking Hammer

In Conclusion, For Vibro Ripper, Due To The Tensile Strength Of The Rock Is Far Less Than The Compressive Strength Of Rock, When Breaking, As Far As Possible To Adopt The Split Rock Way.

Shanghai Shining Machinery Technology Company's Tests And Experience The User Feedback Can Concluded The Efficiency Comparison For Vibro Ripper And Piston Hammer, Which Can Validate The Breaking Mechanism Is Right From The Side ${ }^{[5]}$.

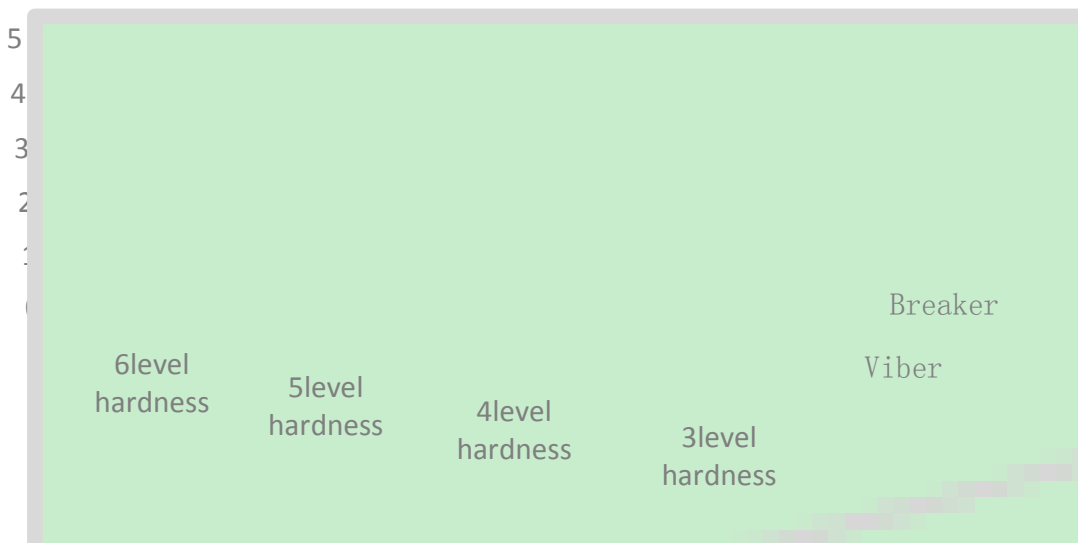

Fig 7 Efficiency Comparison Of Vibro Ripper And Piston Hammer

In The Practical Production Operation, Vibro Ripper Fully Apply To Large Earthmoving Work And Stone Factory Assignments, It Has A Significant Effect On Common Permafrost, Shale, Fault Rock, Sand And Weathered Rock(Fig.7). The Vibro Ripper Designed By Shanghai Shining Machinery Technology Company For Large Earthwork, Optimum Efficiency Is 150 M3 / H, Can Completely Replace The Traditional Hammer.

\section{THE RESEARCH STATUS OF VIBRO RIPPER}

In 1999, The Thyssen. Knut Company Public The Design Drawings Of Vibro Ripper, Until Now The World Has Developed Nearly 5 Kinds Of Vibro Ripper Technology Routes ${ }^{[5]}$, The Two Accounted For In Our Country, The Following Three Prototype For Abroad.

(1) Spain Tabe Company Basically Follows The Original Layout Structure Of The Thyssen. Knut Company, It Adopted The Structure Of Connecting Rod + Airbags+Block, They Changed The Deflected Angle Of The Pieces Eccentric Block ${ }^{[7]}$, Which Improve The Bearing Load, But Reduces The Hitting Force, Products Are Mainly Used For Soft Rock.

(2) Daedong Engineering ${ }^{[8]}$, South Korea Daedong Company After Get The Technical Drawings, Directly Simplify The Hydraulic Vibration Hammer Into Vibro Ripper, But The Structure Is Swollen And It Is Easy To Damage The Rubber Piece When Hooking Stone, They Use The Multi-Layer Steel Rubber Block In The Second Improvement, But Rubber Block Easily Ripped, In The End, They Have To Use The Connecting Rod Structure, Due To There Is No Energy Storage Device, So The Hitting Force Is Little, There Won't Hurt The Hammer .

(3) Spain Xcentric Company ${ }^{[9]}$, Spain Xcentric Company Basically Doesn't Modify The Drawings, Just In Order To Overcome Hammer Head Fatigue Damage Caused By Stress Wave, They Made The Steel Plate Thicken, Which Make Products Become More Heavier, The Excavators Generally Added Counterweight. At 
The Same Time, The Increase Of The Weight Limits The Hit Range, So This Product Is Suitable For Soft Rock Construction.There Are Two Kinds Of Domestic Technical Routes, One Is The Traditional Vibro Ripper That Represented By Shanghai Shining Company, Each Manufacturer's Hammer Structure Is Basically Same, Most Manufacturers Have Done Some Improvement, Including Structure Optimization And Model Segmentation For Hammer Body, Another Route Is Triple Eccentric Vertical Placement Vibro Ripper That Represented By Shanghai Fenyi Mechanical Company. They Groundbreaking Adopted The Form That Triple Eccentric Vertical Placement Balance Inertial Energy Storage And Impact Piston, Striking Effect Are Far Beyond The Traditional Hammer In Hard And Soft Rock Construction.

\section{EXISTING PROBLEMS AND IMPROVEMENT METHODS FOR VIBRO RIPPER}

(1) Frame And Shel Structure Of Vibro Ripper Commonly Exists The Inadequate Strength Problem, After A Period Of Time Work, Breakage And Avulsion Will Happen.

(2) After A Period Of Time Using For Knife Of Vibro Ripper, Avulsion Will Happen, Which Make The Knife Line Prematurely Damage And Improve The User's Maintenance Costs.

(3) Temperature Of Vibration Box Will Rise With The Increase Of Operating Temperature, Used For A Period Of Time, Lubricating Oil Will Deteriorate And Invalidate Due To The Operation Temperature Is Too High.

(4) The Type Of Knife Row Is Too Single And Lack Of Knife Model Selection.

For Vibro Ripper Optimization And Improvement, Especially For Housing, We Can Adopt The Topology Optimization Method For Structural Optimization ${ }^{[10]}$; For The Problem Of High Temperature Of Gear Box, On The One Hand, We Can Use The Higher Quality Gear Oil In View Of The Bad Regional Environment, On The Other Hand, We Can Use The Thermodynamic Analysis Method To Design Cooling Structure; According To Different Rock To Develop The Replaceable Knife Shelf, And Develop The Corresponding Knife Row.

\section{EXPECTATION}

In The Future, The Exploitation Of Vibro Ripper Must Rely On The Demand Of Market. At Present, The Vibro Ripper Cannot Completely Replace The Traditional Piston Hydraulic Hammer, But It's A Complementary Hammer Of Market Segment.

(1)The Vibro Ripper Will Have More Diverse Ways Of Excitation, We Can Use Adjustable Amplitude Technology To Change The Size Of The Vibration Force, Vibration Frequency Also Will Increase Gradually.

(2)Vibro Ripper Will Be More Intelligent, It Can Automatically Adopt Different Exciting Force And Exciting Frequency For Different Rock.

(3)Design Will Be More Humanized, Which Can Reduce The Operation Difficulty And Improve Workplace Conditions.

(4)With The Development, Vibro Rippern With Lower Noise And Emission Will Be More Friendly For Our Environment.

\section{CONCLUSION}

Vibro Ripper As A New Type Of Breaking Hammer Have Many Advantages Including Energy-Saving, Environmental Protection And High Efficiency, There Is A Very Big Advantage In Urban Construction And In Soft Rock Broken Despite It Also Exist Many Problems, It Is Unlikely That Vibro Ripper Completely Replace The Traditional Piston Hammer At This Stage, So, In The Future, The Design Must Be Closely Combine With The Rules Of Market Economy And User Demand, Increasing Investment In Research And Development, Research With Great Concentration, Vibro Ripper Will Occupy The Market.

\section{REFERENCES}

[1] Cao Guojun. A New Vcibroripper: China, 201310178580.9[P]. 2011-4-1.

[2] Hu Kaijun, Yang Guoping, Vibro Ripper Troubleshooting And The Matters Needing Attention [J]. Machine Tool \& Hyd r aulics, 2015, (16):188-190.

[3] Xu Tongle, Xia Mingtang, The Development And Research Status Of Hydraulic Breaking Hammer [J], In:Hydraulics \&Pneumatics \& Sealing. 6. (2005).

[4] Zhou Zhihong, Ma Fei, The Hydraulic Hammer Of The Progress And Shortcomings In China [J], In:Construction Machinery And Equipment. 41, 1. (2010).

[5] Information On Http://Www.Vibrochina.Com

[6] Zhou Jianxin, Zou Xiangfu, Chen Jiangen And He Qinghua, Domestic And Foreign Hydraulic Breaking Hammer Status And Development Tendency Of Research And Development [J], In:Zaoyan Jixie Qidong Gongju. 4. (2001). 
[7] Information On Http://Www.Tabe-Hammers.Com

[8] Information On Http://Www.Maxbrio.Kr

[9] Information On Http://Www.Xcentricripper.Com

[10] Luo Zhen, Chen Liping, Topology Optimization Design Of Continuum Structure [J], Advance In Mechanics, 2001,34(2):463-467. 